NOAA

National Marine

Fisheries Service
Fishery Bulletin

2 established 1881 ๙
Spencer F. Baird

First U.S. Commissione of Fisheries and founder of Fishery Bulletin
Abstract-Understanding how endangered species use nursery habitats is vital for recovery planning. Research on the smalltooth sawfish (Pristis pectinata) has shown that areas of estuarine nurseries, called hotspots, are used consistently. The objectives of our study were 1) to determine whether 10 young-of-theyear smalltooth sawfish in an artificial, non-main-stem portion (i.e., a seawall canal system) of a hotspot were descended from one or different mothers and 2) to document long-term habitat use by these individuals. At least 4 mothers contributed to the group, which comprised siblings, half-siblings, and unrelated individuals. Young sawfish exhibited site fidelity to their capture location, spending $61 \%$ of their time there. Continuous residency lasted as long as 86 days, but these fish made small-scale diel $(<1$ river $\mathrm{km})$ movements between the capture location (day) and the nearby main-riverstem portion of the hotspot (night). Larger-scale (5-7 river $\mathrm{km}$ ) downriver and upriver relocations between the capture location and the river mouth, including 2 other known natural hotspots, occurred after a tropical storm. This research shows that 1) young-of-the-year from different mothers can have high site fidelity at specific locations within a nursery hotspot and 2) these hotspots can be important for young-of-the-year even when there is a drastic change in freshwater inflow.

Manuscript submitted 4 November 2015. Manuscript accepted 12 August 2016. Fish. Bull. 114:461-475 (2016). Online publication date: 1 Sept. 2016. doi: 10.7755/FB.114.4.8

The views and opinions expressed or implied in this article are those of the author (or authors) and do not necessarily reflect the position of the National Marine Fisheries Service, NOAA.

\title{
Long-term site fidelity of endangered smalltooth sawfish (Pristis pectinata) from different mothers
}

\author{
Gregg R. Poulakis (contact author) ${ }^{1,2}$ \\ Philip W. Stevens ${ }^{3}$ \\ Amy A. Timmers ${ }^{1}$ \\ Christopher J. Stafford ${ }^{3}$ \\ Demian D. Chapman 4 \\ Kevin A. Feldheim 5 \\ Michelle R. Heupel6, 7 \\ Caitlin Curtis ${ }^{3}$
}

Email address for contact author: gregg.poulakis@MyFWC.com

\author{
${ }^{1}$ Fish and Wildlife Research Institute \\ Florida Fish and Wildlife Conservation Commission \\ Charlotte Harbor Field Laboratory \\ 585 Prineville Street \\ Port Charlotte, Florida 33954 \\ 2 Department of Marine and Environmental Systems \\ Florida Institute of Technology \\ 150 West University Boulevard \\ Melbourne, Florida 32901 \\ ${ }^{3}$ Fish and Wildlife Research Institute \\ Florida Fish and Wildlife Conservation Commission \\ 100 Eighth Avenue SE \\ St. Petersburg, Florida 33701 \\ ${ }^{4}$ Institute for Ocean Conservation Science \\ School of Marine and Atmospheric Science \\ Stony Brook University \\ Stony Brook, New York 11794
}

\author{
5 Pritzker Laboratory for Molecular \\ Systematics and Evolution \\ The Field Museum \\ 1400 S. Lake Shore Drive \\ Chicago, Illinois 60605 \\ ${ }^{6}$ Australian Institute of Marine Science \\ 1526 Cape Cleveland Road \\ Cape Cleveland, Queensland 4810, Australia \\ ${ }^{7}$ Centre for Sustainable Tropical Fisheries \\ and Aquaculture \\ College of Marine and Environmental \\ Sciences \\ James Cook University \\ 1 Angus Smith Drive \\ Townsville, Queensland 4811, Australia
}

Ecological niche theory (since Grinnell, 1917) and habitat suitability modeling (more recently) have been used to evaluate how the fitness of individuals is linked to their environment (Hutchinson, 1957; Guisan and Zimmermann, 2000). This concept is often extrapolated to the population level in an effort to understand how groups of individuals use their environment. According to a review by Hirzel and Le Lay (2008), the presence of a species depends on 3 location characteristics: 1 ) the location is accessible, 2) the local environment allows the population to grow (Grin- nellian niche, Grinnell, 1917), and 3) interactions with other species (e.g., competition) allow the species to persist (Eltonian niche, Elton, 1927). Further, within a general location at which a species occurs on a variety of spatial scales, smaller portions of the total area (e.g., niche envelopes, coldcore eddies, nursery hotspots) are often more heavily used for reasons related to factors such as food availability, optimal temperature, and reduced predation risk (Jones, 2002; Polovina et al., 2006; Estók, 2007). In teleosts and elasmobranchs, niche characteristics often reflect an onto- 
genetic shift because the importance of different biotic and abiotic factors changes with growth (e.g., Stevens et al., 2007; Grubbs, 2010). For example, reducing predation risk is likely to be more important during early life history stages, whereas access to mates becomes more important for adults (Grubbs, 2010).

For the smalltooth sawfish (Pristis pectinata), which is listed as endangered under the U.S. Endangered Species Act and as critically endangered on the International Union of Conservation of Nature and Natural Resources IUCN Red List of Threatened Species, an understanding of fine-scale patterns of habitat use in the occupied nursery areas in south and southwest Florida has become a priority in recent years for researchers and fishery managers (Fed. Register, 2009; NMFS'; Norton et al., 2012). For example, research data and encounter reports from the public of encountering this species indicate that pregnant females enter nurseries briefly, to give birth, and that juveniles occupy the tidal portions of rivers, estuaries, and coastal bays for approximately their first 3 years (to $\sim 2.2 \mathrm{~m}$ in total length) (Seitz and Poulakis, 2002; Simpfendorfer et al., 2008b, 2010), and larger juveniles and adults are typically found in open-water, marine habitats (Poulakis and Seitz, 2004; Carlson et al., 2014; Waters et al., 2014). Research in the Charlotte Harbor estuarine system has led to important insights into the ecology of juvenile smalltooth sawfish: 1) nursery habitats include main-stem and non-main-stem riverine habitats, and these habitats are used differently throughout ontogeny (Simpfendorfer et al., 2011; Poulakis et al., 2013); 2) juveniles have affinities for specific abiotic conditions during their nursery residency (Poulakis et al., 2011); and 3) responses of juveniles to freshwater inflow-related changes can be delayed (Poulakis et al., 2013).

Multiple lines of evidence, such as higher catch rates and large numbers of acoustic position estimates (estimates of the location of individuals in the study area based on data recorded on acoustic receivers), indicate that juvenile smalltooth sawfish occur at specific locations within estuarine nurseries, areas that are referred to as hotspots (Poulakis et al., 2011, 2013). However, we know little about how these sites are selected, the extent of site fidelity, or what factors influence site fidelity. A nursery hotspot may simply result from a single female giving birth at or near the site, and the young remain there for extended periods. Alternatively, the young may originate from different females that give birth at or near the site or throughout the nursery, and the young converge on or remain at a hotspot because it offers a fitness advantage.

Our objective was to use genetic information and acoustic monitoring of individuals captured at a dis-

\footnotetext{
${ }^{1}$ NMFS (National Marine Fisheries Service). 2009. Recovery plan for smalltooth sawfish (Pristis pectinata), $78 \mathrm{p}$. Prepared by the Smalltooth Sawfish Recovery Team for the National Marine Fisheries Service, Silver Spring, MD. [Available at website.]
}

crete location within a hotspot to test 4 hypotheses regarding their relatedness and movements: 1) related and transient: multiple smalltooth sawfish were found at the location because one female gave birth at or near that location and the young remained there for a brief time period before permanently dispersing more broadly in the estuary; 2) related and resident: multiple smalltooth sawfish were found at the location because one female gave birth at or near that location and the young remained there for an extended time period; 3) not related and transient: multiple smalltooth sawfish were found at the location because multiple females gave birth at or near that location and the young remained there for a brief time period before permanently dispersing more broadly in the estuary; and 4) not related and resident: multiple smalltooth sawfish were found at the location because multiple females gave birth at or near that location and the young remained there for an extended time period.

\section{Materials and methods}

\section{Study area}

One of the largest estuaries in subtropical Florida, the $56-\mathrm{km}$-long $700-\mathrm{km}^{2}$ Charlotte Harbor estuary, is a recognized nursery for the endangered smalltooth sawfish (Seitz and Poulakis, 2002; Poulakis et al., 2011). In 2009, the National Marine Fisheries Service designated most of this estuarine system as 1 of 2 critical habitat areas for juveniles of this species (NMFS, 2009; Norton et al., 2012). To date, most research on smalltooth sawfish has been conducted in the Caloosahatchee River, which is in the southern portion of the estuary, where most of the historical sightings of smalltooth sawfish have been recorded in the Charlotte Harbor system (Seitz and Poulakis, 2002; Poulakis et al., 2011, 2013; Poulakis et al. ${ }^{2}$. The Caloosahatchee River contains 4 of the 5 hotspots where catch rates and the number of acoustic position estimates of smalltooth sawfish have been highest (Poulakis et al., 2011, 2013; Poulakis et al. ${ }^{2}$. Paradoxically, this estuarine river, located adjacent to the cities of Cape Coral and Fort Myers, is one of the most highly altered, flow-managed estuarine waterways in the current range of this species. The fifth hotspot is in the lower Peace River, in the northern portion of the estuarine system, which has a natural freshwater flow regime.

Freshwater inflow into the Caloosahatchee River is regulated by water-control structures (e.g., Franklin Lock) that the South Florida Water Management District uses to manage water levels in Lake Okeechobee,

\footnotetext{
2 Poulakis, G. R., P. W. Stevens, R. D. Grubbs, D. D. Chapman, J. Gelsleichter, G. H. Burgess, T. R. Wiley, J. A. Olin, L. D. Hollensead, A. T. Fisk, et al. 2014. Smalltooth sawfish (Pristis pectinata) research and outreach: an interdisciplinary collaborative program. Final report to the National Marine Fisheries Service for Award NA10NMF4720032. FWRI File-code F2858-10-14-F. 214 p. [Available at website.]
} 
the largest lake in Florida (Stoker, 1992; Chamberlain and Doering, 1998; Barnes, 2005). The anticipation of increased rainfall during the wet season (June-November) or of tropical cyclones approaching the region often prompts water managers to release freshwater from Lake Okeechobee to preclude flooding of surrounding residential and agricultural areas. These freshwater releases occur mainly during the wet season but can also occur during the rest of the year. In general, such changes in freshwater inflow are known to influence habitat use by fish that reside in the tidal portion of the river, including juvenile smalltooth sawfish (Heupel and Simpfendorfer, 2008; Simpfendorfer et al., 2011; Poulakis et al., 2013; Stevens et al., 2013).

Shoreline habitats near the mouth of the Caloosahatchee River, where this study occurred, are fragmented and range from natural shorelines dominated by red mangrove (Rhizophora mangle) to extensive canal systems lined with concrete seawalls. In general, the shallow (depths $<1 \mathrm{~m}$ ) areas dominated by red mangrove have been identified as important habitats for juvenile smalltooth sawfish throughout the current range of this species (NMFS, 2009; Simpfendorfer et al., 2010; Poulakis et al., 2011; Norton et al., 2012).

\section{Field sampling, acoustic equipment, and study development}

This study occurred near the mouth of the Caloosahatchee River during 2006 and 2007 as part of a larger, ongoing research project on smalltooth sawfish. Smalltooth sawfish were sampled primarily with $152-\mathrm{mm}$ stretch-monofilament-mesh gill nets (detailed gear descriptions and sampling protocols are available in Poulakis et al., 2011). Gill nets were soaked for $1 \mathrm{~h}$ and were checked when fish of any type were seen in the net or every $0.5 \mathrm{~h}$, whichever came first. Hook-and-line gear, with live or dead pink shrimp (Farfantepenaeus duorarum) as bait, also was used to capture smalltooth sawfish. Smalltooth sawfish were measured (stretch total length [STL] in millimeters), assessed for overall health, fin-clipped (free rear tip of second dorsal fin; see Genetic analysis section), and tagged (with rototags: $35 \times 9 \mathrm{~mm}$, Dalton ID Systems Ltd. ${ }^{3}$, Henley on Thames, UK; with passive integrated transponders: 12 mm, $134.2 \mathrm{kHz}$, Super Tag II, Biomark Inc., Boise, ID; and with acoustic tags: $29 \mathrm{~mm}$ long, weight in water 2.9 g, 69 kHz, V9-2H-R04K, Vemco, Halifax, Nova Scotia, Canada).

All smalltooth sawfish captured during sampling were tagged with an acoustic tag. The tags were programmed to emit a unique acoustic sequence at $69 \mathrm{kHz}$ on a random delay every $60-180 \mathrm{~s}$. The delays were used to minimize signal collisions when more than one smalltooth sawfish were simultaneously within range of acoustic receivers and to maximize battery life $(\sim 8$

\footnotetext{
${ }^{3}$ Mention of trade names or commercial companies is for identification purposes only and does not imply endorsement by the Florida Fish and Wildlife Conservation Commission or the National Marine Fisheries Service, NOAA.
}

months). In accordance with our endangered species research permit, tags were attached externally, by using a cable tie covered with an epoxy gel, to the flat half of the rototag. As with previous studies (e.g., Whitty et al., 2009), tags were applied to the thicker, anterior margin of the second dorsal fin first by using a leather punch to make a hole for the projecting half of the rototag and then by joining the 2 halves (see photograph in Poulakis, 2012).

Because the smalltooth sawfish is endangered, we distributed signs broadly across the region, encouraging the public to report their encounters with this species (for details about methods used for collecting these data, see Seitz and Poulakis, 2002). In 2006, multiple anglers reported encounters in a small, non-main-stem seawall canal system in the city of Cape Coral (i.e., the Cape Coral capture location) that is part of a larger hotspot near the mouth of the Caloosahatchee River that contains non-main-stem and main-stem habitats (Fig. 1; Poulakis et al. ${ }^{2}$ ). Subsequently, an effort was made to catch, tag with acoustic transmitters, and obtain tissue samples from the second dorsal fin for DNA from individuals at this location. Because no acoustic receivers had been deployed at the capture location before reports of encounters began, 8 VR2 Vemco singlefrequency, omnidirectional data-logging acoustic receivers were deployed and maintained there between May 2006 and September 2007. In addition, 3 receivers were installed in Glover Bight, a non-main-stem embayment near the mouth of the Caloosahatchee River that had previously been identified as a hotspot (Fig. 1; Poulakis et al., 2011), to monitor use of this area by smalltooth sawfish. When combined with data from acoustic receivers already maintained in the main stem of this river to monitor movements of smalltooth sawfish and other species (see Fig. 1; Simpfendorfer et al., 2011), movement between these and other regions of the nursery could be monitored.

Acoustic receivers were placed such that they maximized coverage of the entire study area, including the relatively complex non-main-stem habitats of the $\sim 1$ $\mathrm{km}^{2}$ Cape Coral capture location (referred to as capture location throughout; Fig. 1) and Glover Bight, and continuously recorded the date, time, and identity of all tagged smalltooth sawfish that swam within detection range. The maximum detection range of receivers was estimated as $800 \mathrm{~m}$ (mean= $450 \mathrm{~m}$; Collins et al., 2008). Data were downloaded from receivers and all biofouling was removed approximately every 2 months. A detailed examination of receiver and array performance (e.g., code-detection efficiency, code-rejection coefficients, noise quotients) in the study area can be found in Simpfendorfer et al. (2008a).

The 2 non-main-stem regions of the nursery, which are the focus of this article (i.e., Cape Coral capture location and Glover Bight), were chosen for detailed study because each had one connection to the main stem of the Caloosahatchee River (a single entry and exit point for juveniles; see Fig. 1). These locations allowed unequivocal assessment of the presence or absence of 


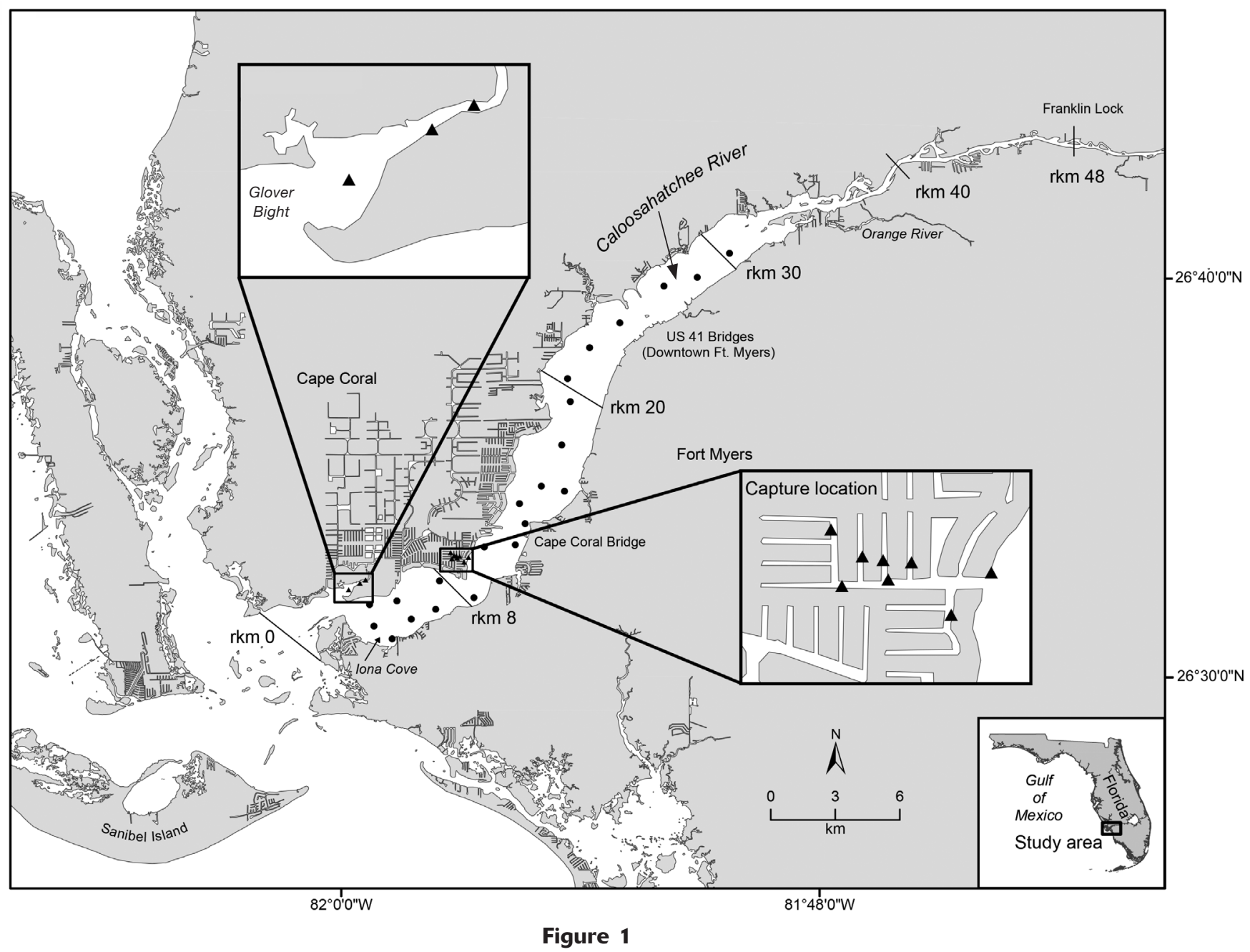

Non-main-stem acoustic receiver arrays (11 receivers, indicated by triangles within the enlargements) and their association with the main-river-stem receiver array (22 receivers, indicated by circles) in the Caloosahatchee River, Florida. Glover Bight and the area around the Cape Coral Bridge, including the Cape Coral capture location used in this study in 2006 and 2007, have been identified as hotspots for juvenile smalltooth sawfish (Pristis pectinata) on the basis of multiple years of scientific catch data, acoustic data, and encounter data from the public (Seitz and Poulakis, 2002; Poulakis et al., 2011; Poulakis et al. ${ }^{2}$ ). River kilometer (rkm) refers to the distance from the river mouth (at rkm 0).

tagged individuals. The capture location was lined entirely by concrete seawalls and had been dredged to a depth of 2-3 m. The substrate was primarily mud with some sand near the corners of the canals. Shorelines in Glover Bight, which includes a natural creek and a small marina, were lined almost entirely by red mangrove and contained a range of water depths from $<1$ $\mathrm{m}$ near shore to $>3 \mathrm{~m}$ near the marina. The substrate was mud in the creek and in deeper areas $(>2 \mathrm{~m})$ and was sand (with the presence of oysters) at the creek mouth and near shore.

\section{Genetic analysis}

Ten juvenile smalltooth sawfish were caught at the capture location in the Caloosahatchee River between April and August 2006. The individuals were all $<1500$ $\mathrm{mm}$ STL, indicating that they were young-of-the-year
(Simpfendorfer et al., 2008b; Scharer et al., 2012). Fin clippings were stored in $95 \%$ reagent-grade ethanol at room temperature. Genomic DNA was extracted by using a PureGene DNA extraction kit (Qiagen Inc., Valencia, CA). Six polymorphic microsatellite loci labeled with fluorescent markers (Feldheim et al., 2010; Table 1) were amplified with 2 multiplexed polymerase chain reactions (PCRs). Approximately $100 \mathrm{ng}$ of template DNA was used in a $12.5-\mu \mathrm{L}$ PCR containing $0.3125 \mathrm{U}$ GoTaq DNA Polymerase (Promega Corp., Madison, WI), $0.8 \mu \mathrm{M}$ of each primer, $200 \mu \mathrm{M}$ of each dNTP, $2.5 \mathrm{mM}$ $\mathrm{MgCl}_{2}, 0.5 \times$ bovine serum albumin (BSA), and $1 \times$ colorless GoTaq buffer. The PCR profile consisted of an initial denaturation at $94^{\circ} \mathrm{C}$ for $2 \mathrm{~min}$, followed by 30 cycles at $94^{\circ} \mathrm{C}$ for $30 \mathrm{~s}, 53^{\circ} \mathrm{C}$ for $30 \mathrm{~s}, 72^{\circ} \mathrm{C}$ for $30 \mathrm{~s}$, and a final extension step at $72^{\circ} \mathrm{C}$ for $5 \mathrm{~min}$.

The resulting fragments were analyzed on an automated Applied Biosystems 3130 Genetic Analyzer 


\section{Table 1}

Microsatellite loci, size of loci (in base pairs), number of alleles $\left(K, K_{\mathrm{T}}, K_{\mathrm{C}}\right.$ ), and corresponding reference for smalltooth sawfish (Pristis pectinata) caught in 2006 in the Caloosahatchee River, Florida. $K$ is the number of alleles per locus for all samples ( $n=10) ; K_{T}$ is the number of alleles per locus for the smalltooth sawfish containing the mitochondrial DNA control region haplotype T $(n=7) ; K_{C}$ is the number of alleles per locus for the smalltooth sawfish containing the mitochondrial DNA control region haplotype $\mathrm{C}(n=3)$.

\begin{tabular}{lcrrrl}
\hline Locus & Size & $K$ & $K_{\mathrm{T}}$ & $K_{\mathrm{C}}$ & \multicolumn{1}{c}{ Reference } \\
\hline Ppe69 & $153-173$ & 4 & 3 & 2 & K. Feldheim, unpubl. data \\
Ppe114 & $181-285$ & 11 & 7 & 5 & Feldheim et al., 2010 \\
Ppe122 & $236-264$ & 6 & 6 & 3 & Feldheim et al., 2010 \\
Ppe160 & $164-174$ & 3 & 2 & 2 & Feldheim et al., 2010 \\
Ppe165 & $251-299$ & 8 & 7 & 4 & Feldheim et al., 2010 \\
Ppe168 & $219-257$ & 8 & 4 & 6 & Feldheim et al., 2010 \\
& & & & & \\
\hline
\end{tabular}

(Thermo Fisher Scientific Inc., Waltham, MA) with GeneScan ROX 500 Size Standard (Thermo Fisher Scientific Inc.). Fragment lengths were analyzed by using GeneMapper software, vers. 4.0 (Applied Biosystems, Thermo Fisher Scientific Inc.), and modified by hand when necessary. Loci were checked for Hardy-Weinberg equilibrium by using GENEPOP (Raymond and Rousset, 1995; Rousset, 2008). The prevalence of null alleles, large allele dropout, and scoring errors was estimated by using MICRO-CHECKER, vers. 2.2.3 (van Oosterhout et al., 2004).

To address our hypotheses, we used a combination of mitochondrial and microsatellite data to conservatively estimate the number of mothers that contributed to the group of smalltooth sawfish. Microsatellite data were analyzed separately within each of the mitochondrial lineages that were identified.

For mitochondrial-DNA sequencing analysis, we amplified a portion of the control region that had approximately 750 base pairs (bp), using the forward primer ProL2 (CTGCCCTTGGCTCCCAAAGC) (Pardini et al., 2001) and reverse primer CRR (ATGCAAATATTATGTCGAGGGTAG) (Phillips et al., 2011). Approximately $100 \mathrm{ng}$ of DNA was used as template in a $50-\mu \mathrm{L}$ PCR reaction containing 1.25 U GoTaq DNA Polymerase, $0.8 \mu \mathrm{M}$ of each primer, $200 \mu \mathrm{M}$ of each dNTP, $2.5 \mathrm{mM} \mathrm{MgCl}{ }_{2}, 0.5 \times \mathrm{BSA}$, and $1 \times$ colorless GoTaq buffer. The PCR profile consisted of an initial denaturation at $94^{\circ} \mathrm{C}$ for 2 min, followed by 30 cycles at $94^{\circ} \mathrm{C}$ for $45 \mathrm{~s}, 52^{\circ} \mathrm{C}$ for $45 \mathrm{~s}, 72^{\circ} \mathrm{C}$ for $45 \mathrm{~s}$, and a final extension step at $72^{\circ} \mathrm{C}$ for $5 \mathrm{~min}$. After amplification, the PCR reaction was run for approximately $45 \mathrm{~min}$ at 90 amps on a $1.5 \%$ TAE agarose gel with ethidium bromide. PCR products were visualized, extracted from the gel, purified by using Stratagene Gel Cleaning spin columns (Agilent Technologies, Santa Clara, CA), and eluted in sterile water.

Purified PCR products were assessed for quantity and quality by using a NanoDrop 2000 microvolume spectrophotometer (Thermo Fisher Scientific Inc.). Ap- proximately $200 \mathrm{ng}$ of each PCR product was cycle-sequenced with ABI Prism BigDye Terminator sequencing mix (Applied Biosystems) by using the following reaction profile: 30 cycles at $95^{\circ} \mathrm{C}$ for $30 \mathrm{~s}, 55^{\circ} \mathrm{C}$ for 15 $\mathrm{s}$, and $72^{\circ} \mathrm{C}$ for $4 \mathrm{~min}$. Sequencing reactions were precipitated with ethanol and sodium acetate, dried for at least $30 \mathrm{~min}$ at $37^{\circ} \mathrm{C}$, and resuspended in $23 \mathrm{~mL}$ of $\mathrm{Hi}-$ Di formamide (Thermo Fisher Scientific Inc.). Samples were analyzed in both directions on an Applied Biosystems 3130xl DNA Analyzer (Thermo Fisher Scientific Inc.). Forward and reverse sequences were assembled into contiguous sequences by using Sequencher, vers. 4.9 (Gene Codes Corp., Ann Arbor, MI) and, when necessary, modified by hand. Primer sequences were identified and excised.

Microsatellite loci exhibited as many as 29 alleles per locus in $>200$ individuals surveyed in southwest Florida and showed high levels of heterozygosity (C. Curtis, unpubl. data). No evidence of null alleles, large allele dropout, or scoring errors was detected with MICRO-CHECKER among the 6 loci, although locus Ppe69 was found to be out of Hardy-Weinberg equilibrium. With 95\% confidence limits and 1000 randomizations, ML-Relate software (Kalinowski et al., 2006) was used to obtain a maximum likelihood estimate of the coefficient of relatedness $(r)$ among potential siblings to estimate the number of mothers represented in the samples.

\section{Movement analysis}

Analysis of acoustic data followed the method of Poulakis et al. (2013). The position of individuals along the Caloosahatchee River was estimated by using a meanposition algorithm (Simpfendorfer et al., 2002, 2008a). Each acoustic receiver was assigned a position along the centerline of the river on the basis of the distance of the receiver from the mouth of the river (the mouth of the river was assigned the position of river kilome- 
ter 0 ; the capture location was assigned the position of river kilometer 10.5). A geographic information system (GIS) layer of the centerline of the river was extracted from the U.S. Geological Survey National Hydrography Dataset (website) and divided into 0.2-km (0.1-nautical mile) segments. The mean position estimates of the location of smalltooth sawfish, averaged in 1-h increments, formed the basis of all subsequent analyses.

In general, a location designation (e.g., present at the capture location) was given only to smalltooth sawfish position estimates that exactly matched the river kilometer values assigned to each acoustic receiver. For example, to be counted as present at the non-mainstem Cape Coral capture location, data from a transmitter had to be recorded on at least one of the interior receivers for an entire hour (i.e., without main-stem detections). A smalltooth sawfish positioned at the entrance of the capture location would have yielded a mean river kilometer position estimate intermediate between the capture location and a nearby main-stem receiver and, therefore, would have been placed in the main stem. Receivers at the capture location and in Glover Bight were isolated from direct acoustic connection with nearby main-stem receivers to help with this determination.

We analyzed movement data for smalltooth sawfish that retained their acoustic tags for at least 25 days. Position estimates for individuals were used to calculate daily activity space (in river kilometers), residence time, and diel activity. As with previous studies (e.g., Simpfendorfer et al., 2011; Poulakis et al., 2013), daily activity space was calculated for each individual as the difference between the most upriver and most downriver position estimates for each day. Main-stem and non-main-stem activity (presence or absence) were calculated for each individual as the percentage of hourly position estimates that corresponded with each habitat. Diel activity was estimated by adding hourly position estimates that occurred during local day (0600-1859) and night (1900-0559) in the 2 habitats for each individual. A chi-square test was used to determine whether the observed day and night position estimates in the 2 habitats (pooling all individuals) differed from an even distribution. The South Florida Water Management District provided data on daily mean freshwater inflow from the Franklin Lock (located at river kilometer 48) for comparison with movement tracks of individual smalltooth sawfish.

\section{Results}

\section{Genetics}

Two mitochondrial haplotypes were identified among the 10 smalltooth sawfish from the capture location. The haplotypes differed by one $\mathrm{C}$ or $\mathrm{T}$ transition. The capture location contained 3 individuals with haplotype $\mathrm{C}$ and 7 individuals with haplotype $\mathrm{T}$ (Table 1 ), indicating that at least 2 mothers had contributed to the group of juveniles sampled because, in vertebrates, mitochondrial DNA is inherited from the mother.

To further refine the number of mothers that contributed to the group, microsatellite data from the 2 mitochondrial groups ( $\mathrm{C}$ and $\mathrm{T}$ ) were analyzed separately using ML-Relate software to estimate the relatedness of individuals within each of the 2 maternal lineages. Within the $\mathrm{C}$ group ( 3 individuals), 2 microsatellite loci (Ppe114 and Ppe168) had more than 4 alleles per locus (Table 1). In the absence of mutation, the maximum number of alleles that can be shared among full siblings at a single locus is 4 . The presence of more than 4 alleles at more than 1 locus indicates that more than 2 parents contributed to the $\mathrm{C}$ group of juveniles because simultaneous, independent mutational events at more than 1 locus are highly unlikely. Within the T group (7 individuals), 3 loci (Ppe114, Ppe122, and Ppe165) contained more than 4 alleles per locus, and 2 of the loci had 7 alleles per locus (Table 1), indicating that more than 2 parents contributed to this group as well. An excess of alleles (i.e., >4) was not observed in loci Ppe69 and Ppe160 for either of the mitochondrial groups. This finding is not inconsistent with more than 2 parents contributing to the group because one or both contributing parents may have been homozygous for the alleles detected for these loci.

The values of $r$ among the 10 unique smalltooth sawfish caught and monitored at the capture location indicate that at least 4 pairs of individuals in the $\mathrm{T}$ group had high $r$ estimates $(\sim 0.5)$ and that those pairs were full-sibling dyads (Table 2). There was a potential half-sibling pair $(r=\sim 0.25)$ in the $\mathrm{C}$ group, along with several unrelated individuals in each mitochondrial lineage. These estimates of relatedness indicate that at least 4 mothers contributed to the 10 individuals. These data support hypotheses 3 and 4 (not related and transient; not related and resident [see more on distinguishing between these hypotheses below]) and are inconsistent with hypotheses 1 and 2 (related and transient; related and resident).

\section{Movements}

Young-of-the-year individuals ranged from 775 to 1218 $\mathrm{mm}$ STL when they were tagged, and mean tag retention was 184 days (standard error [SE] 68.5; Table 3). Half of the 10 individuals were caught on hook and line, and half were caught in gill nets. Six individuals met the analysis criterion of at least 25 days of tag retention. The mean daily activity space of these individuals was 0.7 river $\mathrm{km}$ (SE 0.2 ).

We documented the presence of multiple smalltooth sawfish at the capture location at the same time; on average, individuals spent $61 \%$ of their time there. Up to 4 of the tagged individuals used the capture location at the same time (sawfish 2, 4-6; 1-14 August), and 2 individuals used it at the same time for 2.5 months (sawfish 2 and 4; 1 June-14 August) (Fig. 2). The individual with the longest tag retention (sawfish 4) resided at the capture location for long periods, ranging 


\section{Table 2}

Pairwise coefficients of relatedness $(r)$ among the 10 smalltooth sawfish (Pristis pectinata) caught in 2006 in the Caloosahatchee River, Florida. Pairwise comparisons are shown within each of the 2 mitochondrial DNA lineages (mtDNA haplotypes $\mathrm{C}$ and $\mathrm{T}$ ).

\begin{tabular}{lcc}
\hline Individual pair & $r$ & mtDNA haplotype \\
\hline FWC33: FWC36 & 0.2530 & $\mathrm{C}$ \\
FWC33: FWC38 & 0 & $\mathrm{C}$ \\
FWC36: FWC38 & 0 & $\mathrm{C}$ \\
FWC26: FWC27 & 0 & $\mathrm{~T}$ \\
FWC26: FWC28 & 0.0824 & $\mathrm{~T}$ \\
FWC26: FWC29 & 0.0830 & $\mathrm{~T}$ \\
FWC26: FWC31 & 0.0236 & $\mathrm{~T}$ \\
FWC26: FWC32 & 0.6096 & $\mathrm{~T}$ \\
FWC26: FWC37 & 0.5652 & $\mathrm{~T}$ \\
FWC27: FWC28 & 0.5985 & $\mathrm{~T}$ \\
FWC27: FWC29 & 0 & $\mathrm{~T}$ \\
FWC27: FWC31 & 0.1658 & $\mathrm{~T}$ \\
FWC27: FWC32 & 0 & $\mathrm{~T}$ \\
FWC27: FWC37 & 0 & $\mathrm{~T}$ \\
FWC28: FWC29 & 0 & $\mathrm{~T}$ \\
FWC28: FWC31 & 0 & $\mathrm{~T}$ \\
FWC28: FWC32 & 0 & $\mathrm{~T}$ \\
FWC28: FWC37 & 0.0824 & $\mathrm{~T}$ \\
FWC29: FWC31 & 0.0236 & $\mathrm{~T}$ \\
FWC29: FWC32 & 0.5459 & $\mathrm{~T}$ \\
FWC29: FWC37 & 0.5000 & $\mathrm{~T}$ \\
FWC31: FWC32 & 0.0263 & $\mathrm{~T}$ \\
FWC31: FWC37 & 0.0236 & $\mathrm{~T}$ \\
FWC32: FWC37 & 0 & $\mathrm{~T}$ \\
& & \\
\hline
\end{tabular}

from a few days to as many as 86 consecutive days, without being detected on a main-stem receiver beyond the receiver located at the entrance of the canal system of the capture location. In addition, 3 smalltooth sawfish tagged with acoustic transmitters in the mainstem of the river moved into the capture location array, remaining there for as long as 14 consecutive days.

Tracks of the analyzed individuals showed that daily activity space was limited to a small portion of the study area when smalltooth sawfish were associated with the capture location, but they occasionally moved greater distances (Fig. 3). During September in 2006, after Tropical Storm Ernesto passed over the study area (29 August-1 September), prompting a freshwater release from the Franklin Lock that exceeded $500 \mathrm{~m}^{3} / \mathrm{s}$, 4 individuals (sawfish 3-6) moved downriver away from the capture location to at least river kilometer 5 . At least 3 of these individuals (sawfish 4-6) returned to the capture location after the storm passed, and 1 individual remained in the vicinity of the capture location for at least 10 more months (sawfish 4). After the storm, sawfish 5 and 6 returned to the capture location periodically but continued to make excursions downriver even without large increases in freshwater flow. Sawfish 3 may have exited the river because of the effects of the storm, and sawfish 6 may have exited the river or shed its tag by the end of the year. These data, when combined with the genetic analyses, eliminate hypothesis 3 as a possibility and support hypothesis 4: young-of-the-year smalltooth sawfish that occurred at the capture location were 1) from at least 4 mothers and 2) long-term users of this location.

While they were associated with the capture location, all 4 young-of-the-year smalltooth sawfish that

\section{Table 3}

Summary of movement and habitat use by 6 smalltooth sawfish (Pristis pectinata) after they were tagged and monitored in 2006 and 2007 at the Cape Coral capture location in the Caloosahatchee River, Florida. Individuals are listed in order by date (month/day/year) of first detection from most recently tagged (top) to oldest. Residence time is the percentage of total hourly position estimates that occurred within the non-main-stem seawall canal capture location or in the main stem of the river. Sawfish 4 and 5 were monitored for $\sim 1$ year or more because they were recaptured and re-tagged. Four additional individuals were captured but shed their acoustic tags within a few days (their sizes were 800, 805, 842, 1200 mm stretch total length [STL]). Standard errors (SEs) of the mean are given in parentheses. The asterisk $(*)$ indicates that although the individual was tagged at the capture location on 24 April 2006 the acoustic receivers were not deployed until 22 May 2006.

\begin{tabular}{|c|c|c|c|c|c|c|c|c|}
\hline $\begin{array}{l}\text { Smalltooth } \\
\text { sawfish }\end{array}$ & $\mathrm{STL}(\mathrm{mm})$ & Sex & $\begin{array}{c}\text { Date } \\
\text { of first } \\
\text { detection }\end{array}$ & $\begin{array}{c}\text { Date } \\
\text { of last } \\
\text { detection }\end{array}$ & $\begin{array}{c}\text { Days } \\
\text { monitored }\end{array}$ & $\begin{array}{c}\text { Mean (SE) } \\
\text { daily activity } \\
\text { space }(\mathrm{km})\end{array}$ & $\begin{array}{l}\text { Residence } \\
\text { time in } \\
\text { canals (\%) }\end{array}$ & $\begin{array}{c}\text { Residence } \\
\text { time in } \\
\text { main stem } \\
\text { habitats }(\%)\end{array}$ \\
\hline 6 & 1097 & $\mathrm{~F}$ & 08/01/06 & $12 / 29 / 06$ & 150 & $1.2(0.2)$ & 28.1 & 71.9 \\
\hline 5 & 1218 & $\mathrm{~F}$ & 08/01/06 & 07/19/07 & 352 & $0.7(0.1)$ & 36.7 & 63.3 \\
\hline 4 & 950 & $\mathrm{~F}$ & 06/14/06 & 08/20/07 & 432 & $0.4(0.0)$ & 80.3 & 19.7 \\
\hline 3 & 996 & $\mathrm{~F}$ & 06/07/06 & 08/23/06 & 77 & $1.0(0.3)$ & 70.5 & 29.5 \\
\hline 2 & 1045 & M & 06/07/06 & 08/15/06 & 69 & $0.9(0.1)$ & 51.6 & 48.4 \\
\hline 1 & $775^{*}$ & $\mathrm{~F}$ & $05 / 22 / 06$ & $06 / 16 / 06$ & 25 & $0.0(0.0)$ & 99.7 & 0.3 \\
\hline Mean (SE) & 1013 (SE 61) & & & & $184(\mathrm{SE} 68.5)$ & 0.7 (SE 0.2) & $61.2(\mathrm{SE} 11.1)$ & 38.8 (SE 11.1) \\
\hline
\end{tabular}




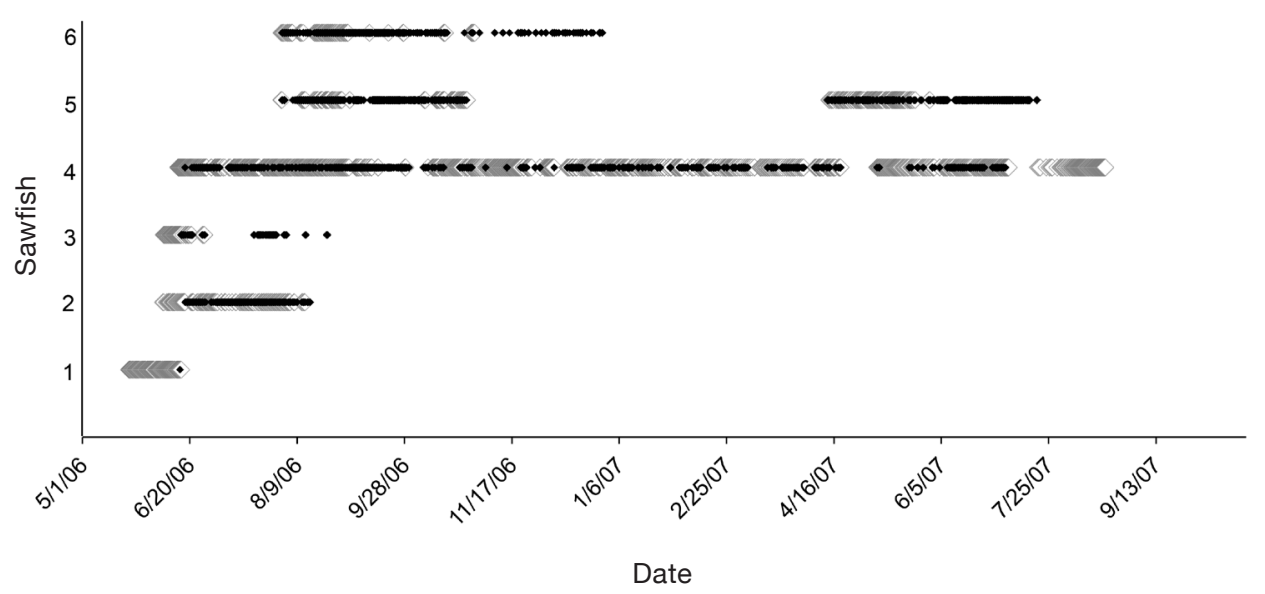

Figure 2

Monitoring histories and activity budgets of 6 smalltooth sawfish (Pristis pectinata) by date (month/day/year) in 2006 and 2007. Large gray diamonds indicate presence at the capture location in Cape Coral, Florida, and small black diamonds indicate presence in the main stem of the Caloosahatchee River. Individuals (sawfish 1-6) are listed chronologically from most recently tagged (top) to oldest in order to correspond with data in Table 3 . See Table 3 for length, sex, dates of first and last detection, days monitored, mean daily activity space, and residence times of each individual.

carried tags for multiple months (sawfish 2, 4-6) periodically exhibited a diel behavioral pattern. They used the capture location throughout the day, but sometimes used the main stem of the river at night (Figs. 4 and 5). Juveniles typically left the capture location and entered the main stem of the river between 1700 and 2200, then left the main stem and returned to the capture location between 0100 and 0700 . These movements occurred as many as 20 times in 1 month. Interestingly, the individual with the longest tag retention and most consistent association with the capture location (sawfish 4) exhibited this pattern the least.

The 3 young-of-the-year smalltooth sawfish with the longest tag retention (sawfish 4-6) used other known nursery hotspots when they left the capture location. One smalltooth sawfish (sawfish 5) exhibited the diel pattern described in the previous paragraph before the passage of Tropical Storm Ernesto and after the storm in another known nursery hotspot, Glover Bight, further downriver (Fig. 5). Before the storm, this individual exhibited the diel pattern associated with the capture location, sometimes not returning to it, but always passing the main-stem acoustic receiver near river kilometer 11.8 at night (Fig. 5A). After the storm, this juvenile moved to Glover Bight (river kilometer 3) and resumed a diel movement pattern there (Fig. 5B). It used a shallow, red-mangrove-lined creek during the day and the deeper, more open waters of red-mangrovelined Glover Bight at night. In addition, the 3 smalltooth sawfish with the longest tag retention times used the Iona Cove hotspot (at river kilometer 5), located on the opposite side of the river from Glover Bight, for short 4- to 5-day periods and for as many as 35 days at a time (Fig. 3).

The total number of smalltooth sawfish position estimates at the capture location and in the main stem (pooling all individuals) differed significantly between day and night, indicating that a diel pattern had occurred (Table 4; $P<0.001, \chi^{2}=208, \mathrm{df}=1$ ). Because the percentages of time spent at the capture location during the day and at night were nearly identical $(49.6 \%$ day and $50.4 \%$ night), the differences detected in the chi-square test were attributed to diel differences in the main stem (33\% day and 67\% night); activity of smalltooth sawfish in the main stem of the river was greater at night than during the day.

\section{Discussion}

The concepts of niche theory and habitat suitability, which link the fitness of individuals to their environment (Hutchinson, 1957; Guisan and Zimmermann, 2000), are especially important to apply to endangered species because their populations are small and their fitness must be maximized to foster recovery. Smaller portions of the total area in which a species occurs (e.g., nursery hotspots) are often more heavily used than other areas for a variety of reasons, such as food availability, optimal temperature, and reduced predation risk (e.g., Jones, 2002; Polovina et al., 2006; Estók, 2007). For smalltooth sawfish, multiple lines of 


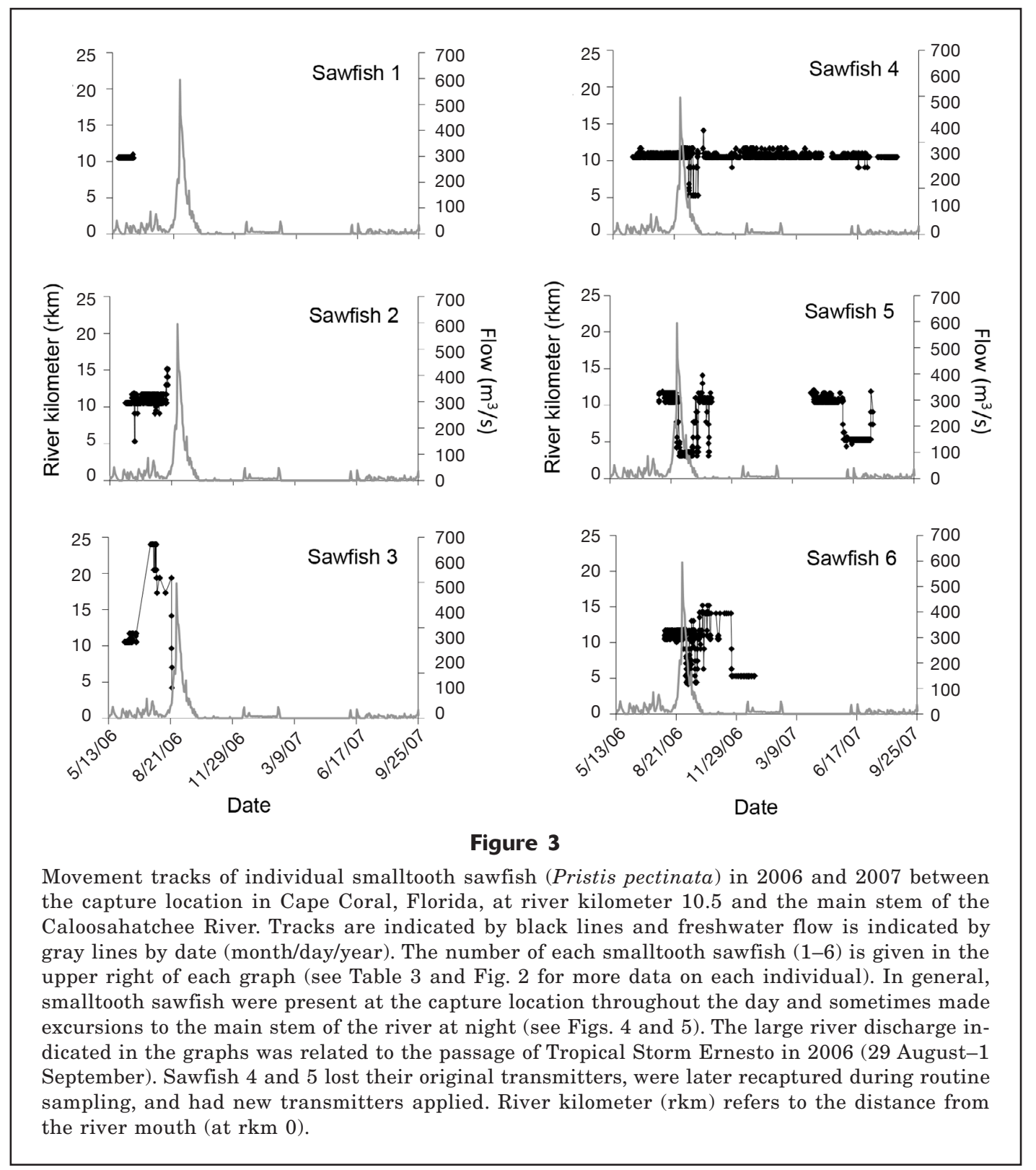

evidence indicate that such nursery hotspots, found throughout much of the species' current range, are consistently important for multiple cohorts of young fish for their first 3 years of life (Poulakis et al., 2011; Hollensead et al., 2016; this study). Similarly, in Australia, researchers have recognized localized capture sites for juvenile sawfishes, including largetooth sawfish $(P$. pristis), dwarf sawfish ( $P$. clavata), and green sawfish (P. zijsron) (Morgan et al., 2011, 2015), indicating that nursery hotspots may also be important for other pristids. These nursery hotspots will likely be an emerging focus of research, management, and conservation.

The DNA and acoustic monitoring results presented here support the hypothesis that a group of youngof-the-year smalltooth sawfish from different mothers occurred in the vicinity of the Cape Coral capture location for extended periods because they had an affinity for that location (hypothesis 4), which is part of a larger hotspot (Poulakis et al. ${ }^{2}$ ). Acoustic tracking and monitoring data from multiple nurseries have shown that young-of-the-year smalltooth sawfish initially have small activity spaces, or home ranges, that increase in size as the fish grow (Simpfendorfer et al., 2010, 2011; Poulakis et al., 2013). Progeny from at least 4 mothers were born in the hotspot at or near the capture location and resided there for their first few weeks of life. The young could have been born elsewhere in the river and converged on the capture location, but, on the basis of previous work in the same river system that showed that the youngest individuals had the smallest 


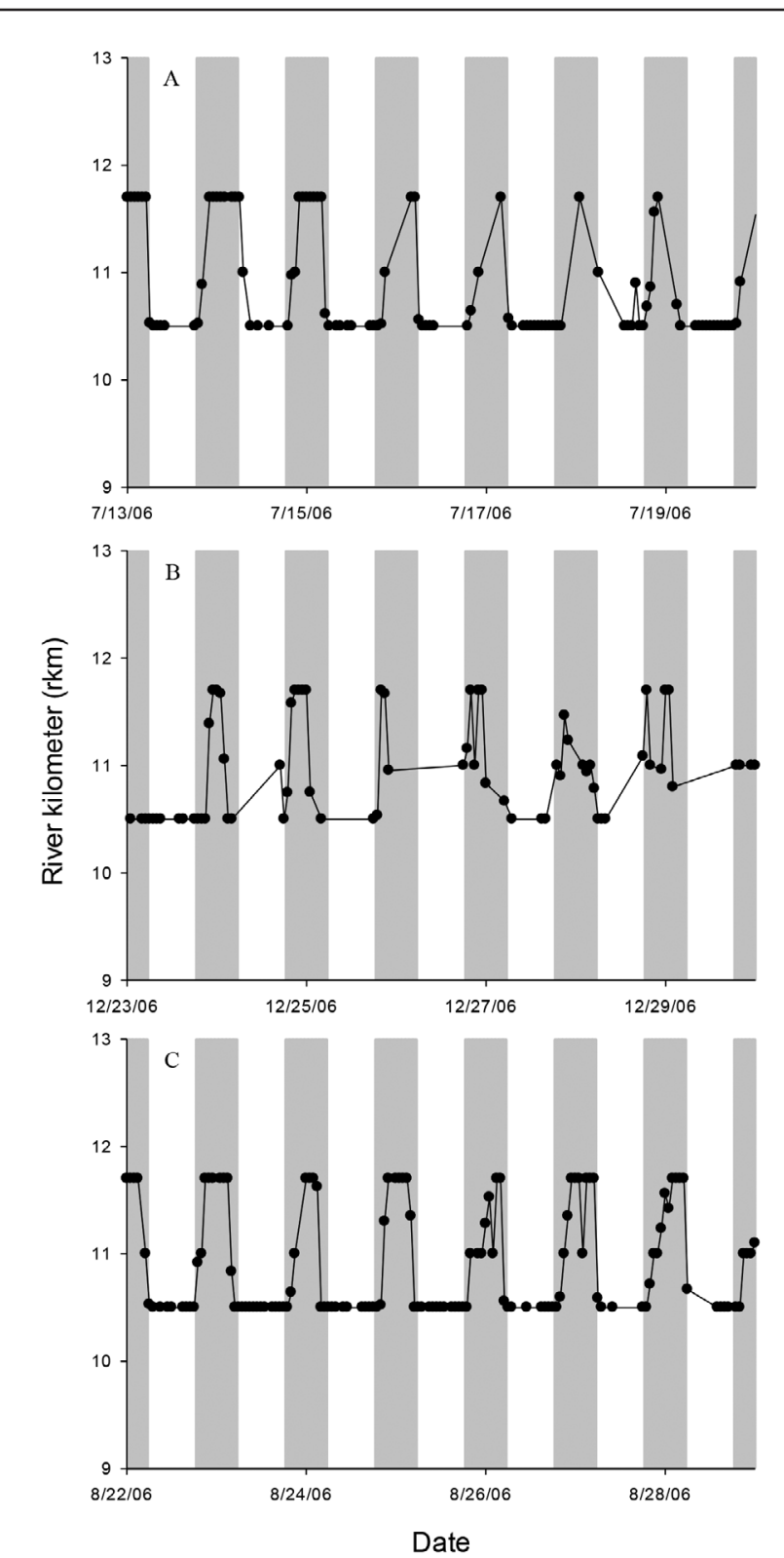

Figure 4

Diel movement patterns of 3 smalltooth sawfish (Pristis pectinata) in 2006 between the capture location (at river kilometer 10.5) in Cape Coral, Florida, and the main stem of the Caloosahatchee River by date (month/day/ year): (A) sawfish 2 (1045 $\mathrm{mm}$ stretch total length [STL]), (B) sawfish 4 (950 mm STL), and (C) sawfish 6 (1097 $\mathrm{mm}$ STL). River kilometer ( $\mathrm{rkm}$ ) refers to the distance from the river mouth (at $\mathrm{rkm} 0$ ). The gray bars indicate night. The acoustic receiver at river kilometer 11 was just outside the entrance to the capture location and the receiver at river kilometer 11.8 was in the main stem of the river near the Cape Coral Bridge (see Fig. 1). In general, these individuals remained within the seawalllined canal system at the capture location during the day, left the capture location and moved into the main stem of the river at night between 1700 and 2200, and returned to the capture location between 0100 and 0700 .

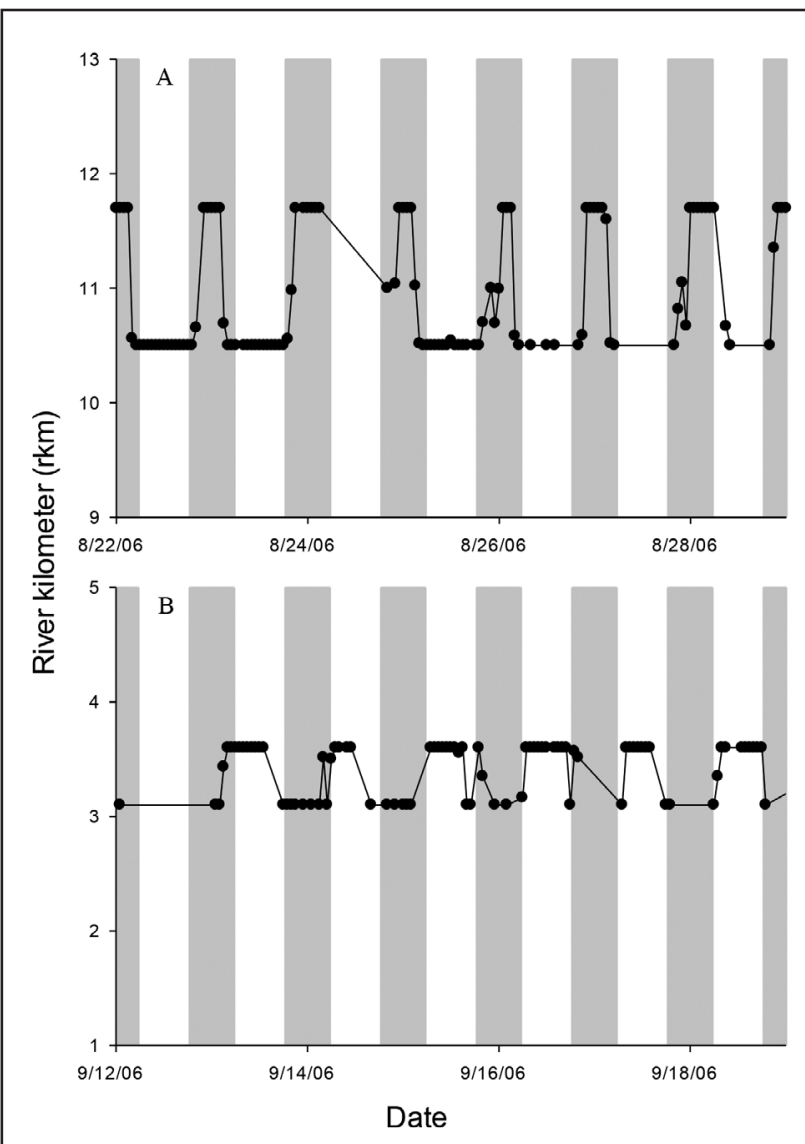

Figure 5

Diel movement patterns of a 1218-mm stretch-totallength smalltooth sawfish (Pristis pectinata) (sawfish 5) that occurred in 2006 at the capture location (at river kilometer 10.5) in Cape Coral, Florida, and at the Glover Bight hotspot by date (month/day/year). River kilometer $(\mathrm{rkm})$ refers to the distance from the river mouth (at rkm 0). The gray bars indicate night. (A) Diel movement pattern between the capture location (day) and the main stem of the Caloosahatchee River (distance from the river mouth $>10.5$ river $\mathrm{km}$; night) leading up to the passage of Tropical Storm Ernesto that occurred 29 August-1 September. (B) Diel movement pattern of the same individual after passage of Tropical Storm Ernesto. Between 13 and 19 September (the only portion shown for detail), this juvenile was located in the natural red-mangrove-lined creek portion of the Glover Bight hotspot (river kilometer 3.6) during the day and moved into the open water portion of Glover Bight at night (river kilometer 3.1) before eventually returning to the capture location (see Fig. 3 for a longer time series).

activity spaces, it seems unlikely (Simpfendorfer et al., 2011). The fact that some of these smalltooth sawfish had a high degree of site fidelity for their capture location, for months at a time, although their activity spaces were predicted to increase as the fish grew, is noteworthy. 


\begin{tabular}{|c|c|c|c|c|c|}
\hline \multicolumn{6}{|c|}{ Table 4} \\
\hline \multicolumn{6}{|c|}{$\begin{array}{l}\text { Diel activity of smalltooth sawfish (Pristis pectinata) monitored at the non-main-stem } \\
\text { Cape Coral capture location and in the main stem of the Caloosahatchee River, Flor- } \\
\text { ida, in } 2006 \text { and } 2007 \text {. The number of position estimates (all individuals pooled) was } \\
\text { significantly greater at night in the main stem of the river }\left(P<0.001, \chi^{2}=208, \mathrm{df}=1\right) \\
\text { STL=stretch total length. }\end{array}$} \\
\hline \multirow[b]{2}{*}{ Smalltooth sawfish } & \multirow[b]{2}{*}{$\mathrm{STL}(\mathrm{mm})$} & \multicolumn{2}{|c|}{$\begin{array}{c}\text { Capture } \\
\text { location activity }\end{array}$} & \multicolumn{2}{|c|}{ Main-stem activity } \\
\hline & & Day & Night & Day & Night \\
\hline 6 & 1097 & 176 & 61 & 114 & 492 \\
\hline 5 & 1218 & 361 & 249 & 489 & 565 \\
\hline 4 & 950 & 1437 & 1892 & 277 & 538 \\
\hline 3 & 996 & 100 & 80 & 22 & 53 \\
\hline 2 & 1045 & 262 & 125 & 60 & 310 \\
\hline 1 & 775 & 207 & 182 & 1 & 0 \\
\hline Total & & 2543 & 2589 & 963 & 1958 \\
\hline
\end{tabular}

Movements of related species associated with small portions of their nurseries have been observed in other systems. Using a variety of data including acoustic tracking, Gruber et al. (1988) documented site fidelity by juvenile lemon shark (Negaprion brevirostris), as well as habitat partitioning by young-of-the-year, juvenile, and adult lemon shark on short (up to 8 days) and long temporal scales. The "nursery zone" of their study area in Bimini, Bahamas, was used by the smallest juveniles and was characterized by the shallowest water and mangrove-fringed shorelines, similar to the habitats used by smalltooth sawfish in their natural hotspots (Poulakis et al., 2011). Using acoustic monitoring, Heupel et al. (2003) documented movements of blacktip shark (Carcharhinus limbatus) away from and back to Terra Ceia Bay (a small bay connected to the Tampa Bay estuary in Florida)-movements that were associated with the passage of a tropical storm. They analyzed several environmental factors and attributed the response of the blacktip shark to changes in barometric and hydrostatic pressure. Collectively, these data are examples of patterns of general habitat-use and the types of environmental cues that influence habitat use by elasmobranchs in localized coastal nurseries (for review, see Simpfendorfer and Heupel, 2012).

Factors influencing the initial use of nursery hotspots by juvenile elasmobranchs could include selection of the area as a birth site by their mothers. Longterm interdisciplinary data have indicated that adult female lemon shark and blacktip shark are philopatric and, therefore, multiple cohorts of juveniles use localized nursery habitats (Feldheim et al., 2004; Hueter et al., 2005; DiBattista et al., 2008). Adult female smalltooth sawfish and largetooth sawfish also have been shown to be philopatric (Phillips et al., 2011; K. Feldheim, unpubl. data); therefore, they are returning to the same general nursery areas to give birth, findings that have implications for management, conservation, and recovery on a large spatial scale.

Upon arrival in the nurseries, pregnant female smalltooth sawfish may give birth to their young in the hotspots rather than more broadly in the river system. In general, these hotspots are close to shore $(<100 \mathrm{~m})$, shallow $(<1 \mathrm{~m})$ and near deeper (at least $2 \mathrm{~m}$ ) water. Hotspots identified in previous studies are currently dominated by shorelines with natural red mangroves and shallow water, and these characteristics have been incorporated into the official critical habitat designation for juvenile smalltooth sawfish (Poulakis et al., 2011; Norton et al., 2012). Historical aerial photographs indicate that the capture location, which was the focus of our study, may have been dominated by shorelines with natural red mangrove and shallow water $(<1 \mathrm{~m})$ before canals were constructed. Whether this site represents a relict habitat, genetically imprinted into the species, or is in fact suitable habitat that provides a fitness advantage for individual smalltooth sawfish is of interest in the context of niche theory.

We document a close association of juvenile smalltooth sawfish with hotspots at a nursery-level spatial scale. Although the entire river was accessible, multiple individuals used the habitats associated with the capture location for months at a time. As in previous studies, however, large-scale movements were observed when juveniles moved downriver as freshwater flows associated with a tropical storm exceeded $500 \mathrm{~m}^{3} / \mathrm{s}$ (Poulakis et al., 2013). That individuals returned to their exact capture location even with its artificial, seawall-canal habitats, after relatively large-scale movements of 5-7 river $\mathrm{km}$ away from the capture location, was somewhat unexpected. It indicates that factors supporting site fidelity (outside the period of the tropical storm), such as adequate food availability, optimal temperature, and reduced predation risk, were satisfied in these artificial habitats. 
At a small spatial scale, a diel activity pattern was observed for multiple individuals at the capture location and for one individual after relocation to a downriver hotspot after a tropical storm. This observation indicates that the factors eliciting these diel behaviors were present at both places. For example, predation pressure may have caused the juveniles to reside in non-main-stem portions of both hotspots during the day, whereas insufficient food may have caused them to move into open-water habitats at night.

In contrast to detection of diel movements, we observed continuous use of the capture location. There are likely multiple explanations for these apparently contradictory behaviors. A portion of the population may favor refuge, continuously occupying habitats off the main stem of the river, such as those in the capture location canal system. The long periods of site fidelity documented at the capture location indicate that adequate food was available there, at least for some individuals. Another portion of the population may be driven to maximize growth and is more likely to venture into the main stem of the river, especially if intraor interspecific competition occurs in the refuge habitat. Those individuals exhibiting a diel pattern may fall between these 2 behaviors. Trade-offs between food and refuge have been discussed thoroughly in the literature on juvenile fish and may help explain the varied movement patterns of juvenile smalltooth sawfish in relation to their nursery hotspots (e.g., for background, see Beck et al., 2001 and Heupel et al., 2007).

There is some support for the idea that predation influences habitat use by juvenile smalltooth sawfish, especially for the smallest individuals. For example, at the Glover Bight hotspot, neonate smalltooth sawfish have been observed among red mangrove prop roots during the day while a shark (species unknown) was feeding in the central portion of the creek (Poulakis et al., 2011; Fig. 1), providing anecdotal evidence that behavior of smalltooth sawfish is influenced by predator avoidance. Further support for the use of nonmain-stem habitats as refuges from predation comes from research that has shown that juvenile bull shark (Carcharhinus leucas), the primary potential predator of juvenile smalltooth sawfish in most nurseries (Simpfendorfer et al., 2005), are more common in the deeper, open-water portions of the Caloosahatchee River (Heupel et al., 2010), which smalltooth sawfish have been observed to often avoid during the day. Juvenile blacktip sharks have exhibited what might also be predatoravoidance behaviors whereby they aggregate during the day and disperse at night (Heupel and Simpfendorfer, 2005).

Feeding is likely to have a major influence on habitat use of smalltooth sawfish because growth is fast in the nursery; smalltooth sawfish double in length during their first year of life (Simpfendorfer et al., 2008b; Scharer et al., 2012). Little is known about the diet of smalltooth sawfish beyond general characterizations and a few observations from field sampling, anglers, and necropsies to document food items, including pink shrimp (as bait) and fish, such as clupeids, carangids, mullet (Mugil spp.), pinfish (Lagodon rhomboides), and a stingray (Dasyatis sp.) (Bigelow and Schroeder, 1953; Poulakis et al., 2013). Traditional stomach-content analyses are not possible because the smalltooth sawfish is endangered; therefore, indirect methods such as analysis of stable isotopes (Fisk et al., 2002) have been employed, and such studies have indicated that fish make up the majority of the diet at all life stages (Poulakis et al. ${ }^{2}$ ).

Monitoring the distribution and abundance of potential prey fish may provide insights into habitat use by smalltooth sawfish. Also, given the distinct side-to-side movements of the rostrum that the smalltooth sawfish uses for feeding (Wueringer et al., 2012), research is underway that uses a novel indirect method, the attachment of acceleration data loggers (Whitney et al., 2012), to monitor potential feeding behavior and may help determine whether food acquisition or other factors (e.g., temperature; Schlaff et al., 2014) contribute to the large-scale relocation of individuals within the nursery or the smaller-scale diel movements observed in this study.

Evidence that movements of juvenile smalltooth sawfish in the nursery are cued, directly or indirectly, by changes in the volume of freshwater inflow (Poulakis et al., 2013) and evidence that juveniles move between nursery hotspots (this study) highlight the need for freshwater inflow management strategies that would minimize the need for these movements in flowmanaged systems such as the Caloosahatchee River (Barnes, 2005). Although there appears to be little predation on smalltooth sawfish in the nursery (Poulakis et al., 2011), predation risk may increase during the time it takes for smalltooth sawfish to find suitable alternate habitats. Predation risk could also increase because predators, like the bull shark, tend to relocate toward the river mouth and co-occur with smalltooth sawfish when freshwater flow increases (Heupel and Simpfendorfer, 2008). As a result, freshwater inflow management strategies that mimic the environmental variability induced by the natural dry and wet seasons may maximize survivorship of smalltooth sawfish (see Poulakis et al., 2011; Simpfendorfer et al., 2011).

Our study was conducted in a highly altered nursery, but the hotspot concept introduced by Poulakis et al. (2011) appears to also apply to smalltooth sawfish in other nurseries. Poulakis et al. ${ }^{2}$ showed that the number of hourly acoustic detections from tagged smalltooth sawfish in upper Charlotte Harbor was greatest in a 2 -river-km portion of the Peace River associated with the only documented hotspot in this river (Poulakis et al., 2011). In 2010-2013, between river kilometers 8 and 10 of the Peace River, there were more than twice the number of hourly detections than there were in either of the 2-river-km sections above and below this location, indicating that for most of their monitoring periods, individuals from multiple cohorts remained in a small region of this large, relatively unaltered river. The high site fidelity to hotspots of juveniles observed 
in the Peace and Caloosahatchee rivers, including the hotspot with artificial habitats in our study, indicates that habitat fragmentation in the highly altered Caloosahatchee River may not be the only factor driving patterns of habitat use there. Therefore, growing evidence indicates that hotspots exist in nurseries throughout the range of smalltooth sawfish, including in regions to the south of the Charlotte Harbor estuarine system, such as the relatively pristine Ten Thousand Islands and Everglades National Park (Simpfendorfer et al., 2010; Hollensead et al., 2016; O'Donnell ${ }^{4}$ ). In these areas, catch rates, acoustic monitoring, and acoustic tracking have all shown high interannual occurrence in hotspot-like areas, such as Faka Union and Mud bays (Simpfendorfer et al., 2010; Hollensead et al., 2016).

Consistent, large-scale acoustic monitoring in these regions would test our hypothesis that hotspots exist in nurseries throughout the range of smalltooth sawfish and would help identify their boundaries. Further, multiple lines of evidence indicate that hotspots also exist for larger ( $>2.2 \mathrm{~m}$ STL) size classes of smalltooth sawfish, after they leave the nurseries, and the same techniques that have been applied in the nurseries are being applied in northwest Florida Bay and off southeast Florida to elucidate the spatial and temporal extent of these high-use areas by smalltooth sawfish (Poulakis and Seitz, 2004; Waters et al., 2014; Papastamatiou et al., 2015). Testing the hotspot concept in a variety of localities and for multiple life stages may help focus future research, management, and conservation efforts for the Pristidae and ultimately promote recovery of these endangered elasmobranchs.

\section{Acknowledgments}

Our research on smalltooth sawfish is ongoing and has been supported primarily by funding from the National Marine Fisheries Service, NOAA, through Section 6 (Cooperation with the States) of the U.S. Endangered Species Act under grant awards to the Florida Fish and Wildlife Conservation Commission from both NOAA (NA06NMF4720032) and the National Fish and Wildlife Foundation (2003-0206-008 and 2004-0012-008). Statements, findings, conclusions, and recommendations are those of the authors and do not necessarily reflect the views or policies of the DOC, NOAA, or the National Fish and Wildlife Foundation. We thank J. Darrow for assistance producing Figure 1, R. Scharer for producing Figures 4 and 5 , and $\mathrm{B}$. Yeiser for access to data recorded on lower-river receivers. D. Adams, J. Adams, B. Crowder, and R. Scharer improved earlier versions of the manuscript. The senior author thanks G. Maul, J. Shenker, E. Irlandi, K. Johnson, and C. Knoll for their support of this work, which was completed to partially fulfill the requirements for his doctoral degree. This research was conducted under Endangered Species Per-

${ }^{4}$ O’Donnell, P. 2014. Unpubl. data. Rookery Bay National Estuarine Research Reserve, Naples, FL 34113 mit number 1475 (FWC) issued by the National Marine Fisheries Service.

\section{Literature cited}

Barnes, $\mathrm{T}$.

2005. Caloosahatchee Estuary conceptual ecological model. Wetlands 25:884-897. Article

Beck, M. W. K. L. Heck Jr., K. W. Able, D. L. Childers, D. B. Eggleston, B. M. Gillanders, B. Halpern, C. G. Hays, K. Hoshino, T. J. Minello, et al.

2001. The identification, conservation, and management of estuarine and marine nurseries for fish and invertebrates. BioScience 51:633-641. Article

Bigelow, H. B., and W. C. Schroeder.

1953. Fishes of the western North Atlantic, Part 2. Sawfishes, guitarfishes, skates, rays, and chimaeroids, 588 p. Mem. Sears Found. Mar. Res., Yale Univ., New Haven, CT.

Carlson, J. K., S. J. B. Gulak, C. A. Simpfendorfer, R. D. Grubbs, J. G. Romine, and G. H. Burgess.

2014. Movement patterns and habitat use of smalltooth sawfish, Pristis pectinata, determined using pop-up satellite archival tags. Aquat. Conserv. 24:104-117. Article

Chamberlain, R. H., and P. H. Doering.

1998. Freshwater inflow to the Caloosahatchee Estuary and the resource-based method for evaluation. In Proceedings of the Charlotte Harbor Public Conference and Technical Symposium. Charlotte Harbor Natl. Est. Program Tech. Rep. 98-02; Punta Gorda, FL, 15-16 March 1997 (S. F. Treat, ed.), p. 81-90. South Florida Water Management District, West Palm Beach, FL.

Collins, A. B., M. R. Heupel, and C. A. Simpfendorfer.

2008. Spatial distribution and long-term movement patterns of cownose rays Rhinoptera bonasus within an estuarine river. Est. Coasts 31:1174-1183. Article

DiBattista, J. D., K. A. Feldheim, X. Thibert-Plante, S. H. Gruber, and A. P. Hendry.

2008. A genetic assessment of polyandry and breedingsite fidelity in lemon sharks. Mol. Ecol. 17:3337-3351. Article

Elton, C.

1927. Animal ecology, 209 p. The Macmillan Co., New York.

Estók, P.

2007. Seasonal changes in the sex ratio of Nyctalus species in north-east Hungary. Acta Zool. Acad. Sci. Hung. 53:89-95

Federal Register

2009. Endangered and threatened species; critical habitat for the endangered distinct population segment of smalltooth sawfish. Fed. Reg. 74:45353-45378.

Feldheim, K. A., S. H. Gruber, and M. V. Ashley.

2004. Reconstruction of parental microsatellite genotypes reveals female polyandry and philopatry in the lemon shark, Negaprion brevirostris. Evolution 58:2332-2342.

Feldheim, K. A., D. D. Chapman, C. A. Simpfendorfer, V. P. Richards, M. S. Shivji, T. R. Wiley, G. R. Poulakis, J. K. Carlson, R. Eng, and S. Sagarese.

2010. Genetic tools to support the conservation of the endangered smalltooth sawfish, Pristis pectinata. Conserv. Genet. Resour. 2:105-113. Article 
Fisk, A. T., S. A. Tittlemier, J. L. Pranschke, and R. J. Norstrom. 2002. Using anthropogenic contaminants and stable isotopes to assess feeding ecology of Greenland sharks. Ecology 83:2162-2172. Article

Grinnell, J.

1917. The niche-relationships of the California thrasher. The Auk 34:427-433. Article

Grubbs, R. D.

2010. Ontogenetic shifts in movements and habitat use. In Sharks and their relatives II: biodiversity, adaptive physiology, and conservation (J. C. Carrier, J. A. Musick, and M. R. Heithaus, eds.), p. 319-350. CRC Press, Boca Raton, FL.

Gruber, S. H., D. R. Nelson, and J. F. Morrissey.

1988. Patterns of activity and space utilization of lemon sharks, Negaprion brevirostris, in a shallow Bahamian lagoon. Bull. Mar. Sci. 43:61-76.

Guisan, A., and N. E. Zimmermann.

2000. Predictive habitat distribution models in ecology. Ecol. Model. 135:147-186. Article

Heupel, M. R., and C. A. Simpfendorfer.

2005. Quantitative analysis of aggregation behavior in juvenile blacktip sharks. Mar. Biol. 147:1239-1249. Article

2008. Movement and distribution of young bull sharks Carcharhinus leucas in a variable estuarine environment. Aquat. Biol. 1:277-289. Article

Heupel, M. R., C. A. Simpfendorfer, and R. E. Hueter.

2003. Running before the storm: blacktip sharks respond to falling barometric pressure associated with Tropical Storm Gabrielle. J. Fish Biol. 63:1357-1363. Article

Heupel, M. R., J. K. Carlson, and C. A. Simpfendorfer.

2007. Shark nursery areas: concepts, definition, characterization and assumptions. Mar. Ecol. Prog. Ser. 337:287-297. Article

Heupel, M. R., B. G. Yeiser, A. B. Collins, L. Ortega, and C. A. Simpfendorfer.

2010. Long-term presence and movement patterns of juvenile bull sharks, Carcharhinus leucas, in an estuarine river system. Mar. Freshw. Res. 61:1-10. Article

Hirzel, A. H., and G. Le Lay.

2008. Habitat suitability modelling and niche theory. J. Appl. Ecol. 45:1372-1381. Article

Hollensead, L. D., R. D. Grubbs, J. K. Carlson, and D. M. Bethea.

2016. Analysis of fine-scale daily movement patterns of juvenile Pristis pectinata within a nursery habitat. Aquat. Conserv. 26:492-505. Article

Hueter, R. E., M. R. Heupel, E. J. Heist, and D. B. Keeney.

2005. Evidence of philopatry in sharks and implications for the management of shark fisheries. J. Northwest Atl. Fish. Sci. 35:239-247.

Hutchinson, G. E.

1957. Concluding remarks. Population studies: animal ecology and demography. Cold Spring Harbor Symp. Quant. Biol. 22:415-427.

Jones, C. M.

2002. Age and growth. In Fishery science: the unique contributions of early life stages. (L. A. Fuiman and R. G. Werner, eds.), p. 33-63. Blackwell Science, Oxford, UK.

Kalinowski, S. T., A. P. Wagner, and M. L. Taper.

2006. ML-RELATE: a computer program for maximum likelihood estimation of relatedness and relationship. Mol. Ecol. Notes 6:576-579. Article
Morgan, D. L., J. M. Whitty, N. M. Phillips, D. C. Thorburn, J. A. Chaplin, and R. McAuley.

2011. North-western Australia as a hotspot for endangered elasmobranchs with particular reference to sawfishes and the northern river shark. J. R. Soc. West. Aust. 94:345-358.

Morgan, D. L., M. G. Allen, B. C. Ebner, J. M. Whitty, and S. J. Beatty.

2015. Discovery of a pupping site and nursery for critically endangered green sawfish Pristis zijsron. J. Fish Biol. 86:1658-1663. Article

Norton, S. L., T. R. Wiley, J. K. Carlson, A. L. Frick, G. R. Poulakis, and C. A. Simpfendorfer.

2012. Designating critical habitat for juvenile endangered smalltooth sawfish in the United States. Mar. Coast. Fish. 4:473-480. Article

Papastamatiou, Y. P., R. D. Grubbs, J. Imhoff, S. J. B. Gulak, J. K. Carlson, and G. H. Burgess.

2015. A subtropical embayment serves as essential habitat for sub-adults and adults of the critically endangered smalltooth sawfish. Global Ecol. Conserv. 3:764-775. Article

Pardini, A. T., C. S. Jones, L. R. Noble, B. Kreiser, H. Malcolm, B. D. Bruce, J. D. Stevens, G. Cliff, M. C. Scholl, M. Francis, et al.

2001. Sex-biased dispersal of great white sharks. $\mathrm{Na}$ ture 412:139-140.

Phillips, N. M., J. A. Chaplin, D. L. Morgan, and S. C. Peverell. 2011. Population genetic structure and genetic diversity of three critically endangered Pristis sawfishes in Australian waters. Mar. Biol. 158:903-915. Article

Polovina, J., I. Uchida, G. Balazs, E. A. Howell, D. Parker, and P. Dutton.

2006. The Kuroshio Extension Bifurcation Region: a pelagic hotspot for juvenile loggerhead sea turtles. DeepSea Res., II 53:326-339. Article

Poulakis, G. R.

2012. Distribution, habitat use, and movements of juvenile smalltooth sawfish, Pristis pectinata, in the Charlotte Harbor estuarine system, Florida. Ph.D. diss., 165 p. Florida Inst. Tech., Melbourne, Florida.

Poulakis, G. R., and J. C. Seitz.

2004. Recent occurrence of the smalltooth sawfish, Pristis pectinata (Elasmobranchiomorphi: Pristidae), in Florida Bay and the Florida Keys, with comments on sawfish ecology. Fla. Sci. 67:27-35.

Poulakis, G. R., P. W. Stevens, A. A. Timmers, T. R. Wiley, and C. A. Simpfendorfer.

2011. Abiotic affinities and spatiotemporal distribution of endangered smalltooth sawfish, Pristis pectinata, in a south-western Florida nursery. Mar. Freshw. Res. 62:1165-1177. Article

Poulakis, G. R., P. W. Stevens, A. A. Timmers, C. J. Stafford, and C. A. Simpfendorfer.

2013. Movements of juvenile endangered smalltooth sawfish, Pristis pectinata, in an estuarine river system: use of non-main-stem river habitats and lagged responses to freshwater inflow-related changes. Environ. Biol. Fish. 96:763-778. Article

Raymond, M., and F. Rousset.

1995. GENEPOP (version 1.2): population genetics software for exact tests and ecumenicism. J. Hered. $86: 248-249$.

Rousset, F.

2008. GENEPOP '007: a complete re-implementation of 
the GENEPOP software for Windows and Linux. Mol. Ecol. Resour. 8:103-106. Article

Scharer, R. M., W. F. Patterson III, J. K. Carlson, and G. R. Poulakis.

2012. Age and growth of endangered smalltooth sawfish (Pristis pectinata) verified with LA-ICP-MS analysis of vertebrae. PLoS ONE 7(10):e47850. Article

Schlaff, A. M., M. R. Heupel, and C. A. Simpfendorfer.

2014. Influence of environmental factors on shark and ray movement, behavior and habitat use: a review. Rev. Fish Biol. Fish. 24:1089-1103. Article

Seitz, J. C., and G. R. Poulakis.

2002. Recent occurrence of sawfishes (Elasmobranchiomorphi: Pristidae) along the southwest coast of Florida (USA). Fla. Sci. 65:256-266.

Simpfendorfer, C. A., and M. R. Heupel.

2012. Assessing habitat use and movement. In Biology of sharks and their relatives, 2nd ed. (J. C. Carrier, J. A. Musick, and M. R. Heithaus, eds.), p. 579-601. CRC Press, Boca Raton, FL.

Simpfendorfer, C. A., M. R. Heupel, and R. E. Hueter.

2002. Estimation of short-term centers of activity from an array of omnidirectional hydrophones and its use in studying animal movements. Can. J. Fish. Aquat. Sci. 59:23-32. Article

Simpfendorfer, C. A., G. G. Freitas, T. R. Wiley, and M. R. Heupel.

2005. Distribution and habitat partitioning of immature bull sharks (Carcharhinus leucas) in a southwest Florida estuary. Estuaries 28:78-85. Article

Simpfendorfer, C. A., M. R. Heupel, and A. B. Collins.

2008a. Variation in the performance of acoustic receivers and its implication for positioning algorithms in a riverine setting. Can. J. Fish. Aquat. Sci. 65:482-492. Article

Simpfendorfer, C. A., G. R. Poulakis, P. M. O’Donnell, and T. R. Wiley.

2008b. Growth rates of juvenile smalltooth sawfish Pristis pectinata Latham in the western Atlantic. J. Fish Biol. 72:711-723. Article

Simpfendorfer, C. A., T. R. Wiley, and B. G. Yeiser.

2010. Improving conservation planning for an endangered sawfish using data from acoustic telemetry. Biol. Conserv. 143:1460-1469. Article

Simpfendorfer, C. A., B. G. Yeiser, T. R. Wiley, G. R. Poulakis, P. W. Stevens, and M. R. Heupel.

2011. Environmental influences on the spatial ecology of juvenile smalltooth sawfish (Pristis pectinata): results from acoustic monitoring. PLoS ONE 6(2):e16918. Article

Stevens, P. W., D. A. Blewett, and G. R. Poulakis.

2007. Variable habitat use by juvenile common snook, Centropomus undecimalis (Pisces: Centropomidae): applying a life-history model in a southwest Florida estuary. Bull. Mar. Sci. 80:93-108.

Stevens, P. W., M. F. D. Greenwood, and D. A. Blewett.

2013. Fish assemblages in the oligohaline stretch of a southwest Florida river during periods of extreme freshwater inflow variation. Trans. Am. Fish. Soc. 142:1644-1658. Article

Stoker, Y. E.

1992. Salinity distribution and variation with freshwater inflow and tide, and potential changes in salinity due to altered freshwater inflow in the Charlotte Harbor estuarine system, Florida. U.S. Geological Survey, Water-Resour. Invest. Rep. 92-4062, 30 p. [Available at website.]

van Oosterhout, C., W. F. Hutchinson, D. P. M. Wills, and P. Shipley.

2004. MICRO-CHECKER: software for identifying and correcting genotyping errors in microsatellite data. Mol Ecol. Notes 4:535-538. Article

Waters, J. D., R. Coelho, J. Fernandez-Carvalho, A. A. Timmers, T. Wiley, J. C. Seitz, M. T. McDavitt, G. H. Burgess, and G. R. Poulakis.

2014. Use of encounter data to model spatio-temporal distribution patterns of endangered smalltooth sawfish, Pristis pectinata, in the western Atlantic. Aquat. Conserv. 24:760-776. Article

Whitney, N. M., Y. P. Papastamatiou, and A. C. Gleiss.

2012. Integrative multisensory tagging: emerging techniques to link elasmobranch behavior, physiology, and ecology. In Biology of sharks and their relatives, 2nd ed. (J. C. Carrier, J. A. Musick, and M. R. Heithaus, eds.), p. 265-290. CRC Press, Boca Raton, FL.

Whitty, J. M., D. L. Morgan, S. C. Peverell, D. C. Thorburn, and S. J. Beatty.

2009. Ontogenetic depth partitioning by juvenile freshwater sawfish (Pristis microdon: Pristidae) in a riverine environment. Mar. Freshw. Res. 60:306-316. Article

Wueringer, B. E., L. Squire Jr., S. M. Kajiura, N. S. Hart, and S. P. Collin.

2012. The function of the sawfish's saw. Current Biol. 22:R150-R151. Article 